\title{
Effects of Lumbar Stabilization Exercise Program Using Respiratory Resistance on Pain, Dysfunction, Psychosocial Factor, Respiratory Pressure in Female Patients in 40's with Low Back Pain: Randomized Controlled Trial
}

\author{
${ }^{1}$ Sam-Ho Park, ${ }^{1}$ Youn-Jung Oh, ${ }^{2}$ Seung-Hwa Jung, ${ }^{3}$ Myung-Mo Lee* \\ ${ }^{1}$ Department of Physical Therapy, Graduate School, Daejeon University, Republic of Korea. ${ }^{2}$ Department \\ of Physical Therapy, Graduate School, Konyang University, Republic of Korea. ${ }^{3}$ Department of Physical \\ Therapy, Daejeon University, Republic of Korea.
}

Submitted 13 October 2020; Accepted in final form 12 November 2020.

\begin{abstract}
Background. Middle-aged women are at risk of musculoskeletal disorders because of the decreased muscle mass and bone density caused by a decreased endocrine function. Objectives. This study investigated the effectiveness of a stabilization exercise using respiratory resistance on female patients in their 40s with low back pain. Methods. Fortyfour female patients in their 40s with low back pain were assigned randomly to an experimental $(n=22)$ or control group $(n=22)$. The experimental group performed lumbar stabilization exercises along with respiratory resistance, and the control group only performed lumbar stabilization exercises, both groups for $60 \mathrm{~min}$ per session, three sessions a week, for four weeks. The numeric rating scale (NRS), Korean-Oswestry disability index (K-ODI), Fear-Avoidance Beliefs Questionnaire (FABQ), static balance ability maximum inspiratory pressure (MIP), and maximum expiratory pressure (MEP) were measured before and after the intervention program. Results. Both groups showed significant differences in the NRS, K-ODI, FABQ, center of pressure (CoP) velocity, MIP, and MEP before and after the intervention $(\mathrm{p}<0.05)$. In the length and area of CoP, only the experimental group showed a significant difference $(\mathrm{p}$ $<0.05)$. In the experimental group, the K-ODI, FABQ, balance ability, MIP, and MEP showed significantly better improvement than the control group ( $\mathrm{p}<0.05)$. Conclusion. A lumbar stabilization exercise program using the respiratory resistance is an effective method with increased motor function, psychosocial stability, significant improvement in balance, and respiratory pressure in women in their 40s with low back pain.
\end{abstract}

KEYWORDS: Low back Pain, Respiration, Respiratory resistance, Static balance ability, Maximum Inspiratory Pressure, Maximum Expiratory Pressure

\section{INTRODUCTION}

Low back pain (LBP) is a musculoskeletal disorder that frequently occurs in modern society. The disorder is experienced at least once in approximately $90 \%$ of adults, and such back pain increases the psychological, economic, and social burdens (1). Unlike the past, current jobs are causing physical activity shortages and lifestyle changes due to automation and office work. These changes have led to a weakening of the abdominal muscles and an imbalance of the body, further leading to serious health problems, such as lumbar deformity $(2,3)$.

LBP is caused by poor lifestyle and lack of exercise, and the incidence increases with

*. Corresponding Author:

Myung-Mo Lee, Ph.D.

E-mail: mmlee@dju.kr 
increasing age in women than in men (4). Middleaged women are in a period of physical aging. Changes in social structure and participation in economic activities have increased, leading to increased stress and physical and psychological burdens both at home and work (5). In particular, females in their late forties at the beginning of menopause show degenerative changes in the lumbar spine due to a decrease in muscle mass and bone density caused by a decrease in female hormones induced by a decrease in endocrine function (6).

An unstable lumbar spine causes abnormal alignment or imbalance and delivers excess gravity and weight to the lumbar spine (7). In addition, the lumbar muscle strength and endurance, and exercise control ability are reduced (8), which causes constant stimulation and stress on the lumbar area. These stimuli and stresses cause the patient to feel physically and mentally uncomfortable, while at the same time appear to decrease the functional motor control skills, such as walking, sitting and daily activities $(9,10)$. This causes emotional problems, such as anxiety, depression, helplessness, and poor quality of life, as back pain progresses (11).

A dysfunction of the abdominal muscles is associated with LBP (12). The abdominal muscles provide mechanical support to the spine and pelvis, so an instability between the muscles increases if the muscles are not contracted properly (13). Research on lumbar stabilization exercises to improve the stability and function of the abdominal muscles has been actively conducted (14-16). Through this, an exercise program that can improve both the correct posture and balance ability should be performed in parallel (17).

An abdominal drawing-in maneuver (ADIM) has been implemented as a selective training method for the diaphragm and abdominal muscles for LBP. This maneuver is often used in clinical practice to improve symptoms through neuromuscular retraining in patients with LBP and lumbar instability (18). To improve the respiratory function, a contraction of the diaphragm is effective in training respiratory resistance (19). This improves the diaphragm muscle strength and endurance by applying a load to the diaphragm by regulating the flow of air entering during inhalation. In addition, when applied together with a lumbar stabilization exercise program, it solves the instability of the lumbar region (20) and helps improve the lumbar stability $(16,21)$.

Studies on the effectiveness of respiratory resistance training and stabilization exercises in relation to LBP have been actively conducted, but the reported studies on middle-aged women in their 40s with LBP have been insufficient. This study examined the effects of a stabilization program with respiratory resistance on women in their 40s with LBP on the patient's pain level, dysfunction, psychosocial factors, balance ability, maximum inspiratory pressure (MIP), and maximum expiratory pressure (MEP).

\section{MATERIALS AND METHODS}

Participants. This study was conducted on 65 female patients in their 40s who were hospitalized for LBP at P Hospital in D City. The inclusion criteria were (1) patients who had experienced LBP at least within the past six weeks, (2) a score of 3 or higher in the numeric rating scale (NRS), (3) three or more positives among the five lumbar instability tests, (4) and people who could stand on one leg for $30 \mathrm{~s}$. The exclusion criteria were patients who had difficulties in motor performance due to pain, participated in less than $80 \%$ of the sessions, and had systemic and respiratory diseases, such as cancer, and patients who had compression fractures. The purpose and process of the study were explained to all participants, and they all signed a written consent form that their participation was voluntary. This study was approved by the Ethics Committee and is registered in the WHO International Clinical Trials Registry Platform: KCT0005233.

Procedures. This research was a singleblinded, randomized, control trial study. The sample size was calculated using G-power 3.19 software. The alpha level and power were set to 0.05 and 0.8 , respectively. According to a previous pilot test, the effective size was set to 0.91 ; at least 20 participants were required in each group. On the other hand, the minimum number of participants to be selected was 22 after considering a potential dropout rate of $10 \%$ (22). This was a randomized control trial, in which the recruited participants underwent lumbar instability testing for selection screening. Lumbar instability testing consisted of the following: 1 . lumbar instability test in the prone position, 2 . lumbar posterior-anterior mobility test, 3 . straight leg raising test, 4. passive lumbar extension test, and 5. under 40 years of age (23). After the 
lumbar instability screening tests, this study excluded 21 patients who had positive results in two or fewer tests $(n=15)$ and a score of 3 or lower in the NRS $(n=6)$. To compare the effects of the interventions, 44 participants were assigned randomly to the experimental group $(n=22)$ or the control group $(n=22)$ using a randomization program (24). The participants were not given information about the group to which they had been assigned. The experimental group performed a lumbar stabilization exercise program using respiratory resistance training, and the control group performed only a lumbar stabilization exercise program. All interventions were provided $60 \mathrm{~min}$ a session, three sessions a week, for four weeks. Both groups were measured for the NRS, Korean version of Oswestry disability index (K-ODI), Fear-Avoidance Beliefs Questionnaire (FABQ), static balance ability, MIP, and MEP before and after the intervention. Data after the post-test assessments were recorded for analysis.

\section{Lumbar Stabilization Exercise Program.} Both groups were given the lumbar stabilization exercise program, which was a modification of the intervention method of Boucher (2016) (25). The stabilization exercise program is an exercise that induces stabilization by controlling the pressure applied from the outside through a contraction of the abdominal muscles and cocontraction of the lumbar muscles. The program consisted of six exercises: curl up, dead bug, superman, bird dog, bridge, and side plank with knee flexion. Stretching for $10 \mathrm{~min}$ was performed to warm up and cool down before and after the sessions. Each movement was made for five sets consisting of five repetitions and $10 \mathrm{~s}$ each repetition, with a $20 \mathrm{~s}$ break between each set. The intervention was implemented for four weeks, three times a week, and $60 \mathrm{~min}$ per session.

Curl up - the participants bent both knees in supine. After that, they placed both hands to their chest, and then slowly lifted their chest, shoulders, and head.

Side flank with knee flexion - The participants laid on their side with their knees bent. After that, one shoulder was maintained at $90^{\circ}$ to support the trunk, and the pelvis and upper body were lifted to place the opposite arm on the side with the pelvis and knee support. After holding for $5 \mathrm{~s}$, the other side was also executed.
Bridge - The participant immediately bent both knees in the prone position, and then lifted the pelvis in alignment with the thigh.

Dead bug - The participants bent both knees in the supine position. After that, one arm was raised vertically, and the other leg was bent at the knee to keep the shin bone parallel to the floor. After holding for $5 \mathrm{~s}$, the other side was also executed.

Superman - The participant lifted both arms and legs in the prone position.

Bird dog - The participants were in a fourlegged pose. After that, one arm was lifted, and the other leg was parallel to the floor. After holding for $5 \mathrm{~s}$, the other side was also executed.

Lumbar Stabilization Exercise Program Using Respiratory Resistance. The experimental group performed breathing resistance training simultaneously with the lumbar stabilization exercise program. The exercise program was performed using a respiration-resisting device (Expand-a-Lung®, Miami, USA) that was composed of a silicone mouthpiece and a valve that controls ventilation. The respiration-resisting device controls the amount of ventilation during inhalation and exhalation and results in a resistance of airflow for respiratory muscle strengthening. Using a respiration-resisting device, the resistance level was set to a stage where the participants could stay below 14 in the Borg's rating of perceived exertion (26).

The lumbar stabilization exercise program using respiratory resistance was as follows (Figure 1).

\section{Outcome Measures}

Pain Level. To identify the pain levels of the participants following the intervention program, the NRS was used. This test was a self-assessment questionnaire, 0 means no pain, 5 means moderate pain, and 10 means unbearable pain. The reliability was high $(\mathrm{r}=0.61)(1)$.

Dysfunction Level. K-ODI was used to assess the level of dysfunction in patients with LBP. The K-ODI suggested by Kim (2005) was used to assess the level of dysfunction due to LBP (27). This assessment consisted of nine items: pain level, personal hygiene, lifting objects, walking, sitting, standing, sleeping, social participation, travel, and mobility. The scores range from zero to five, and the highest possible score was 45 . The reliability of K-ODI was high $(r=0.92)$ (28). 
Psychosocial Factor. FABQ was used to determine the level of the psychosocial factors in patients with LBP. The FABQ is a self-reported questionnaire that assesses the relationships of the fear-avoidance response, LBP, and dysfunction (29). Five items related to physical activities in FABQ-PA and 11 items related to work in FABQ-
$\mathrm{W}$ were given on a seven-point scale $(0=$ Totally disagree, $6=$ Perfectly agree) for self-assessment. The score range of FABQ was 0-66; a higher score means a stronger degree. The FABQ Joo (2009) was used, and the reliability of this test was 0.95 .

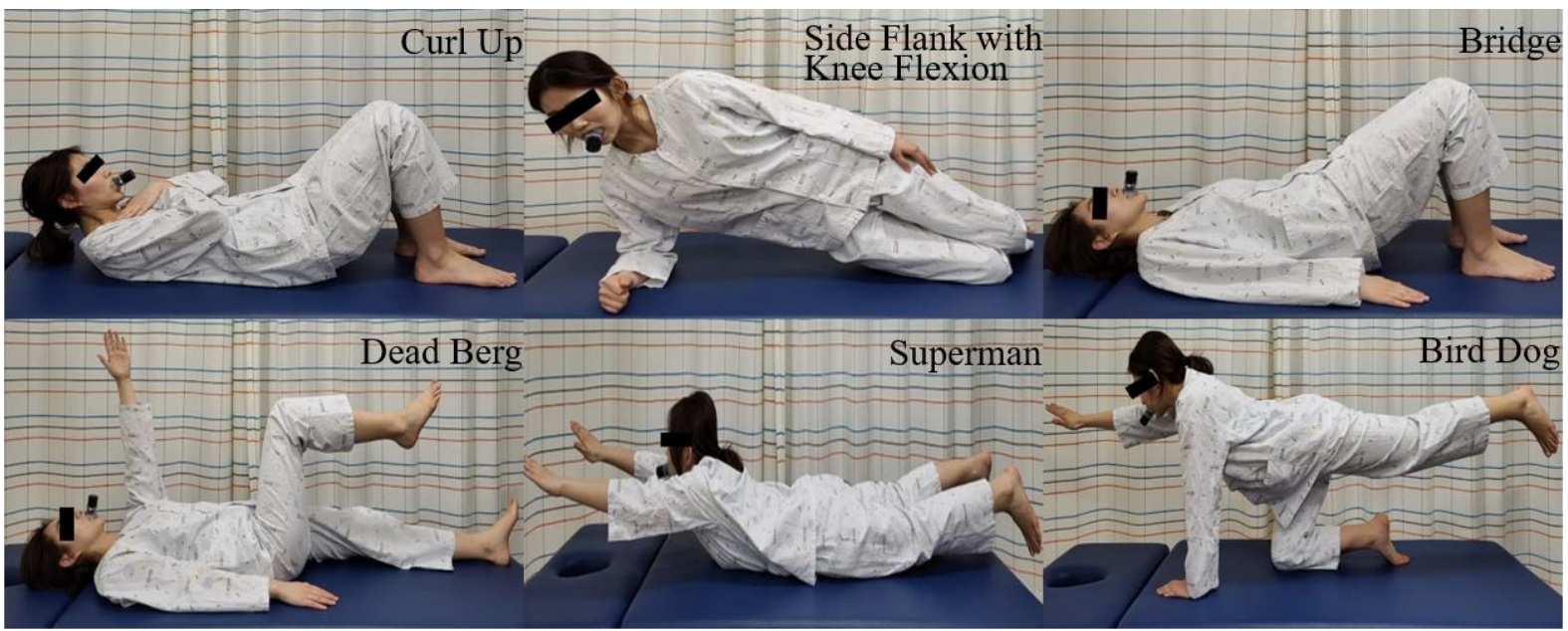

Figure 1. Lumbar Stabilization Exercise using Respiratory Resistance

Balance Ability. A Wii balance board (WBB) (Nintendo, Kyoto, Japan) was used to measure the static balance ability according to the intervention method. The participants stepped on top of the platform WBB to track the sway from the center of pressure $(\mathrm{CoP})$ to derive the path length, velocity, and area 95\%. Participants who partook in the study climbed over the WBB and performed one-leg standing motion with the dominant leg, as directed by the physical therapist. The postural disturbances coming from vision was controlled by asking the participants to focus on a dot $15 \mathrm{~cm}$ in diameter and $3 \mathrm{~m}$ away. The average value measured in three trials was collected using the Balancia program (Mintosys, Seoul, Republic of Korea). The inter-rater reliability of the Wii Balance Board was ICC = 0.92-0.98 (30), and the Balancia program was a helpful assessment tool that standardized the inter-rater reliability $(\mathrm{r}=0.79-0.96)$ and validity $(\mathrm{r}=0.85-0.96)(31)$.

Respiratory Pressure. The subjective Respiratory Pressure of the participants was assessed using a Micro RPM (Carefusion, San Diego, USA). The participants stretched their shoulders in a standing position and spread their legs shoulder width. A mouthpiece equipped with the micro RPM was placed in the mouth, and MIP and MEP were measured. Sufficient rest was provided between MIP and MEP. The maximum value of three measurements was used for data analysis.

Statistical Analysis. Data analysis was performed using SPSS version 21.0 (IBM, Chicago, IL, USA). The general characteristics of the participants were provided using the mean and standard deviation values through descriptive statistics, and the Shapiro-Wilk test was used for normality testing. The normal distribution of all variables from the results was identified. The general characteristics between groups and the homogeneity test of the pre-intervention values were analyzed using a chi-squared test and t-test. An independent-samples t-test and chi-squared test were used to compare the intervention results between the groups, and the paired t-test was used to compare the dependent variables within the groups. Statistical significance was set at $\mathrm{P}<$ 0.05 .

\section{RESULT}

Four patients were excluded as a result of early discharge from the experimental group and the control group, and the data from the total experiment $(\mathrm{n}=20)$ and control group $(\mathrm{n}=20)$ were collected. The general characteristics were similar in the two groups (Table 1). 
Table 1. General Characteristics. (Mean $\pm \mathrm{SE}$ )

\begin{tabular}{lcccc}
\hline & Experimental Group $(\mathbf{n = 2 0})$ & Control Group $(\mathbf{n}=\mathbf{2 0})$ & $\mathbf{t} / \boldsymbol{\chi} \mathbf{2}$ & P \\
\hline Age $($ year) & $47.09 \pm 1.15$ & $46.68 \pm 1.73$ & 0.924 & 0.361 \\
Height $(\mathbf{c m})$ & $157.86 \pm 3.15$ & $158.73 \pm 2.35$ & -1.030 & 0.309 \\
Weight $(\mathbf{k g})$ & $59.27 \pm 3.52$ & $60.64 \pm 5.59$ & -0.968 & 0.339 \\
BMI $\left(\mathbf{k g} \mathbf{m}^{2}\right)$ & $20.84 \pm 1.26$ & $20.63 \pm 1.21$ & 0.572 & 0.570 \\
Onset $($ month) & $18.45 \pm 2.40$ & $18.36 \pm 1.62$ & 0.147 & 0.884 \\
\hline
\end{tabular}

BMI: body mass index.

Table 2. Comparison of Dependent Variables According to the Intervention between Groups. (Mean \pm SE)

\begin{tabular}{|c|c|c|c|}
\hline & Experimental Group $(n=20)$ & Control Group $(\mathbf{n}=\mathbf{2 0})$ & $t(p)^{a}$ \\
\hline \multicolumn{4}{|l|}{ NRS (score) } \\
\hline Pre & $6.40 \pm 0.47$ & $6.44 \pm 0.42$ & $-0.336(0.738)$ \\
\hline Post & $4.24 \pm 0.35$ & $4.45 \pm 0.42$ & \\
\hline Post-pre & $-2.16 \pm 0.65$ & $-1.99 \pm 0.52$ & $1.149(0.264)$ \\
\hline$t(p)^{b}$ & $-15.628(0.000)$ & $-17.928(0.000)$ & \\
\hline \multicolumn{4}{|l|}{ ODI (score) } \\
\hline Pre & $17.32 \pm 5.9$ & $16.09 \pm 4.24$ & $0.792(0.433)$ \\
\hline Post & $9.45 \pm 3.92$ & $10.95 \pm 4.36$ & \\
\hline Post-pre & $-7.86 \pm 3.77$ & $-5.14 \pm 4.02$ & $2.295(0.032)$ \\
\hline $\mathrm{t}(\mathrm{p})$ & $-9.782(0.000)$ & $-6.000(0.000)$ & \\
\hline \multicolumn{4}{|c|}{ FABQ-PA (score) } \\
\hline Pre & $22.36 \pm 1.84$ & $21.73 \pm 2.16$ & $1.051(0.299)$ \\
\hline Post & $14.28 \pm 3.31$ & $19.73 \pm 2.55$ & \\
\hline Post-pre & $-8.14 \pm 4.03$ & $-2.00 \pm 2.76$ & $5.849(0.000)$ \\
\hline $\mathrm{t}(\mathrm{p})$ & $-9.476(0.000)$ & $-3.399(0.003)$ & \\
\hline \multicolumn{4}{|c|}{ FABQ-W (score) } \\
\hline Pre & $40.41 \pm 2.48$ & $39.18 \pm 2.81$ & $1.537(0.132)$ \\
\hline Post & $26.05 \pm 6.62$ & $29.73 \pm 6.01$ & \\
\hline Post-pre & $-14.36 \pm 5.95$ & $-9.45 \pm 5.81$ & $3.483(0.002)$ \\
\hline$t(p)$ & $-11.326(0.000)$ & $-7.630(0.000)$ & \\
\hline \multicolumn{4}{|c|}{ FABQ-total (score) } \\
\hline Pre & $62.77 \pm 3.21$ & $60.91 \pm 3.95$ & $1.718(0.093)$ \\
\hline Post & $40.32 \pm 6.66$ & $49.41 \pm 6.88$ & \\
\hline Post-pre & $-22.45 \pm 6.12$ & $-11.50 \pm 6.80$ & $5.937(0.000)$ \\
\hline$t(p)$ & $-17.199(0.000)$ & $-7.930(0.000)$ & \\
\hline
\end{tabular}

${ }^{a}$ Independent-samples t-test. ${ }^{b}$ Paired t-test. NRS, numeric rating scale. ODI, oswestry disability index. FABQ-PA, fearavoidance beliefs questionnaire-physical activity. FABQ-W, fear-avoidance beliefs questionnaire-work.

Table 3. Comparison of Dependent Variables According to the Intervention between Groups (Mean $\pm \mathrm{SE}$ )

\begin{tabular}{|c|c|c|c|}
\hline & Experimental Group $(\mathbf{n}=20)$ & Control Group $(\mathbf{n}=20)$ & $t(p)^{a}$ \\
\hline \multicolumn{4}{|c|}{ CoP velocity $(\mathrm{cm} / \mathrm{s})$} \\
\hline Pre & $4.70 \pm 0.82$ & $4.69 \pm 0.83$ & $0.051(0.959)$ \\
\hline Post & $3.66 \pm 0.66$ & $4.10 \pm 0.75$ & \\
\hline Post-pre & $-1.04 \pm 0.99$ & $-0.59 \pm 1.06$ & $2.903(0.009)$ \\
\hline$t(p)^{b}$ & $-4.962(0.000)$ & $-2.623(0.016)$ & \\
\hline \multicolumn{4}{|c|}{ CoP length (cm) } \\
\hline Pre & $135.51 \pm 20.08$ & $140.13 \pm 21.15$ & $-0.743(0.462)$ \\
\hline Post & $110.03 \pm 19.71$ & $130.73 \pm 19.58$ & \\
\hline Post-pre & $-25.48 \pm 18.11$ & $-9.40 \pm 29.65$ & $2.602(0.017)$ \\
\hline $\mathrm{t}(\mathrm{p})$ & $-6.600(0.000)$ & $-1.486(0.152)$ & \\
\hline \multicolumn{4}{|c|}{$\mathrm{CoP}$ area $\left(\mathrm{cm}^{2}\right)$} \\
\hline Pre & $8.39 \pm 2.95$ & $8.64 \pm 2.79$ & $-0.286(0.777)$ \\
\hline Post & $5.56 \pm 2.16$ & $7.52 \pm 2.30$ & \\
\hline Post-pre & $-2.83 \pm 2.57$ & $-1.12 \pm 3.73$ & $2.481(0.022)$ \\
\hline $\mathrm{t}(\mathrm{p})$ & $-5.170(0.000)$ & $-1.406(0.174)$ & \\
\hline \multicolumn{4}{|c|}{$\operatorname{MIP}\left(\mathrm{cm} \mathrm{H} \mathrm{H}_{2} \mathrm{O}\right)$} \\
\hline Pre & $-64.18 \pm 7.06$ & $-63.65 \pm 6.06$ & $-0.263(0.793)$ \\
\hline Post & $-85.67 \pm 6.39$ & $-64.63 \pm 6.46$ & \\
\hline Post-pre & $-21.50 \pm 3.99$ & $-0.98 \pm 2.06$ & $19.407(0.000)$ \\
\hline$t(p)$ & $-25.213(0.000)$ & $-2.224(0.037)$ & \\
\hline \multicolumn{4}{|c|}{$\operatorname{MEP}\left(\mathrm{cm} \mathrm{H}_{2} \mathrm{O}\right)$} \\
\hline Pre & $77.30 \pm 8.85$ & $76.08 \pm 6.66$ & $0.514(0.610)$ \\
\hline Post & $85.48 \pm 7.99$ & $77.13 \pm 6.28$ & \\
\hline Post-pre & $8.19 \pm 1.55$ & $1.05 \pm 1.59$ & $-17.587(0.000)$ \\
\hline $\mathrm{t}(\mathrm{p})$ & $24.740(0.000)$ & $3.091(0.006)$ & \\
\hline
\end{tabular}


In both groups, the previous values of the dependent variables were homogenous.

Both groups showed significant differences $(\mathrm{P}$ $<0.05)$ in these parameters after the intervention. In addition, the differences in the ODI and FABQ between the groups showed a significant increase in the experimental group compared to the control group $(\mathrm{P}<0.05)$ (Table 2).

Both groups showed significant differences $(\mathrm{P}$ $<0.05)$ in the CoP velocity, MIP, and MEP after the intervention. In addition, the differences in the balance ability, MIP, and MEP between the groups showed a significant increase in the experimental group compared to the control group $(\mathrm{P}<0.05)$ (Table 3$)$.

\section{DISCUSSION}

This study compared the effects of a lumbar stabilization exercise program with and without respiration resistance on female patients with LBP in their 40's. Significant improvement of the motor function, psychosocial stability, balance ability, and respiratory muscle strength during inspiration and expiration were noted in the experimental group that performed stabilization exercise using respiratory resistance $(\mathrm{P}<0.05)$.

Middle-aged women have a risk of LBP due to decreased hormones, pregnancy, and childbirth because of their physiological characteristics (32). In addition, as aging progresses, physical changes occur along with decreases muscle strength, muscle volume, and muscle endurance (27). Han (2010) (33) reported that in the case of female LBP, the joints were more stressed due to the increased shear force applied to the lumbar spine because of an increase in the inclination angle of the lumbar lordosis and lumbosacral. Lumbar instability occurs due to physical changes, and chronic LBP results if it continues (34). The stabilization exercises for chronic LBP strengthens the core muscles through isometric contractions of the abdominal muscles, which improves the lumbar stability (35).

Han (2010) reported that in women with LBP, the pain increased due to the increased pressure of the lumbar spine caused by an abnormal increase in shear force due to lumbar hyperlordosis. Park and An (2017) reported that stabilization exercise was effective on the pain levels in women in their $30 \mathrm{~s}$ and 40 s with chronic back pain $(\mathrm{P}<0.05, \mathrm{~d}=$ $0.50)$ (36). This study also revealed significant differences in the experimental group $(\mathrm{d}=5.21)$, who performed the lumbar stabilization exercise program using respiratory resistance, and the control group $(d=4.74)$, who performed only the lumbar stabilization exercise program, which is consistent with the results of a previous study ( $\mathrm{P}$ $<0.05)$. Although there was no significant difference between the two groups, a larger effect size was found in the experimental group using respiratory resistance. The stabilization exercise program presented as an exercise program was to activate the muscles around the lumbar spine and abdomen to help improve the stability of the trunk (27) In particular, the strong contraction of the abdomen contributed more to the stability of the trunk during the development of respiratory resistance in the experimental group.

The quality of life decreases when a dysfunction caused by LBP increases the difficulty in daily life (37). This study evaluated the motor dysfunction and pain level of the subjects. Excluding the items related to sexual activities, a percentage was derived from the 45 points total. The level of motor dysfunction decreased from $37 \%$ to $20 \%$ and $35 \%$ to $24 \%$ in the experimental and control group, respectively ( $\mathrm{P}<0.05)$. In addition, statistically significant improvement was found in the experimental group using the respiratory resistance compared to the control group $(\mathrm{P}<0.05)$. This is thought to have affected the level of pain and dysfunction caused by increased intra-vertebral pressure and increased intra-abdominal pressure due to the stronger contractions during inspiration and expiration.

Back pain causes psychological changes that caused the individual to avoid physical activities and work, potentially causing fibrosis and atrophy (16). Accordingly, the Korean version of FABQ was used to examine the fear-avoidance response before and after the intervention. As a result, the level of psychological anxiety was decreased significantly in both groups participating in the study $(\mathrm{P}<0.05)$. In addition, compared to the control group, the experimental group using respiratory resistance showed a more significant difference $(\mathrm{P}<0.05)$. In the experimental group in which stabilization exercise was performed using respiratory resistance, the decrease in the fear of physical movement and daily activities was greater as the ability of exercise function increased through stronger deep muscle contraction.

Jo (2011) reported that in the case of a patient with LBP, the trunk stability was reduced 
compared to a healthy adult without back pain when examining one leg with the dominant leg. In this study, the balance ability was evaluated by one leg standing to evaluate the movement performance of women with LBP. As a result, there was a significant difference in the velocity, path length, and area $95 \%$ of CoP between the experimental using respiratory resistance and the control group $(\mathrm{P}<0.05)$. In the case of LBP, mobilization and muscle activity of the deep muscles of the trunk and the muscles of the hip joint are different from those of normal persons when one leg standing is performed (38). To prevent and reduce dysfunction, muscles of the trunk of the body should be strengthened, and unnecessary exercise should be prevented (39). Through this, the stabilization exercise using respiratory resistance contributed to the stability of the trunk by increasing the co-contraction of the deep muscles responsible for stabilizing the trunk muscles. As a result, the indicator of balance ability was improved. The respiratory pressure test is a non-invasive method that measures the muscle strength of the inspiratory and expiration muscles and used as a test to measure the ventilation and respiratory insufficiency during inspiration and expiration (40-42). In this study, a stabilization exercise using breathing resistance was conducted to examine the change in respiratory pressure. As a result, all participants in this study who conducted the exercise programs showed significant improvement in the respiratory pressure $(\mathrm{P}<$ 0.05). In addition, in the experimental group using the respiratory resistance showed a greater difference than in the control group $(\mathrm{P}<0.05)$. This is believed to have contributed to the respiratory muscle strength because of the contractile capacity of the lung and strengthening of the diaphragm muscle during inspiration through respiratory resistance training. As a result, high-intensity respiratory resistance training of stabilization exercise using respiratory resistance increased the stability of the lumbar spine. In addition, it helped improve the motor function, psychosocial stability, and balance ability by affecting the abdominal muscle contractility due to the improvement of respiratory muscle strength. This study had some limitations. First, the participants in the study consisted only of women in their 40s, making it difficult to generalize to men of the same age or patients with LBP. Second, incorrect breathing occurs when participants breathe simultaneously through the nose and mouth using a breathing resistor. To prevent this, breathing was induced only by the mouth, and the exercise program using a breathing resistor was unfamiliar. Therefore, an adaptation period of approximately one to two days and prior practice are required. Third, although the amount of change in the respiratory pressure was confirmed through the respiratory resistor, the amount of change in lung vitality was not confirmed.

\section{CONCLUSION}

This study examined the effects of a lumbar stabilization exercise program using respiratory resistance on the pain, dysfunction, psychosocial factor, balance ability, and respiratory pressure of female patients in their 40s with LBP. The results showed an increased motor function, psychosocial stability, significant improvement in balance, and respiratory pressure. These results show that lumbar stabilization exercise using respiratory resistance is beneficial to patients with female patients in their 40s with LBP. Future studies will modify the difficulty levels of respiratory resistance training, and encourage interest in the stabilization exercise program to increase respiratory functions and decrease the LBP effectively.

\section{APPLICABLE REMARKS}

This study supports that a lumbar stabilization exercise program using respiratory resistance can improve motor function, psychosocial stability, balance and respiratory pressure in female patients in their 40s with LBP.

\section{CONFLICTS OF INTEREST}

No potential conflict of interest relevant to this article was reported.

\section{ACKNOWLEDGEMENTS}

This research was supported by the Daejeon University fund (2020).

\section{REFERENCES}

1. Maher CG, Latimer J, Hodges PW, Refshauge KM, Moseley GL, Herbert RD, et al. The effect of motor control exercise versus placebo in patients with chronic low back pain [ACTRN012605000262606]. BMC Musculoskeletal Disorder. 2005;6(1):54. doi: 10.1186/1471-2474-6-54 pmid: 16271149 
2. Tsao H, Druitt TR, Schollum TM, Hodges PW. Motor training of the lumbar paraspinal muscles induces immediate changes in motor coordination in patients with recurrent low back pain. J Pain. 2010;11(11):1120-1128. doi: 10.1016/j.jpain.2010.02.004 pmid: 20434958

3. Park JH, Kang JI, Kim KJ. The physical therapy of musculoskeletal disease. Seoul: Hyunmoonsa. 2012.

4. Arab AM, Behbahani RB, Lorestani L, Azari A. Assessment of pelvic floor muscle function in women with and without low back pain using transabdominal ultrasound. Manual Therap. 2010;15(3):235-239. doi: 10.1016/j.math.2009.12.005 pmid: 20089440

5. Kim SY, Jang KT. Effects of weight training and plyometric training on muscle strength and functional physical ability in middle-aged women. J Life Sci. 2001;40:697-706.

6. Yoo EK, Kim MH, Kim TK. A study of the relationship among health promoting behaviors, climacteric symptoms and depression of middle-aged women. J Korean Academ Nurs. 1999;29(2):225-237. doi: 10.4040/jkan.1999.29.2.225

7. Lee SJ, Kim YM. The effects of gluteal muscle exercises combined lumbar stabilization on lumbar stability in chronic low back pain patients with lumbar instability. J Korean Societ Physic Med. 2013;8(1):29-39. doi: 10.13066/kspm.2013.8.1.029

8. Lee H-O. Activation of trunk muscles during stabilization exercises in four-point kneeling. $J$ Korean Physic Therap. 2010;22.

9. McConnell J. Recalcitrant chronic low back and leg pain - a new theory and different approach to management. Manual therapy. 2002;7(4):183-192. doi: 10.1054/math.2002.0478 pmid: 12481782

10.Lin CWC, McAuley JH, Macedo L, Barnett DC, Smeets RJ, Verbunt JA. Relationship between physical activity and disability in low back pain: a systematic review and meta-analysis. PAIN®. 2011;152(3):607-613. doi: 10.1016/j.pain.2010.11.034

11. Gatchel RJ, Bernstein D, Stowell AW, Pransky G. Psychosocial differences between high-risk acute vs. chronic low back pain patients. Pain practice. 2008;8(2):91-97. doi: 10.1111/j.1533-2500.2008.00176.x pmid: 18366464

12. Arab AM, Behbahani RB, Lorestani L, Azari A. Correlation of digital palpation and transabdominal ultrasound for assessment of pelvic floor muscle contraction. Journal of Manual \& Manipulative Therapy. 2009;17(3):75E-79E. doi: 10.1179/jmt.2009.17.3.75E pmid: 20046616

13. Sapsford R. Rehabilitation of pelvic floor muscles utilizing trunk stabilization. Manual Therap. 2004;9(1):3-12. doi: 10.1016/S1356-689X(03)00131-0

14.Behm DG, Drinkwater EJ, Willardson JM, Cowley PM. The use of instability to train the core musculature. Appl physiol Nutrition Metabolism. 2010;35(1):91-108. doi: 10.1139/H09-127 pmid: 20130672

15. Son HH. Trunk Muscle Activation during Bridge Exercise with Various Shoulder Supporting Surfaces. J Korean Societ Physic Med. 2015;10(3):81-86. doi: 10.13066/kspm.2015.10.3.81

16.Park SH, Lee MM. Effects of a Progressive Stabilization Exercise Program Using Respiratory Resistance for Patients with Lumbar Instability: A Randomized Controlled Trial. Med Sci Monitor Int Med J Experiment Clinic Res. 2019;25:1740. doi: 10.12659/MSM.913036 pmid: 30842392

17.Lim NY, Yi YJ. The effects of Koryo hand-acupuncture on the patients with chronic low back pain. $J$ Korean Academ Nurs. 2003;33(1):79-86. doi: 10.4040/jkan.2003.33.1.79 pmid: 15314467

18. Macedo LG, Maher CG, Latimer J, McAuley JH. Motor control exercise for persistent, nonspecific low back pain: a systematic review. Physic Therap. 2009;89(1):9-25. doi: 10.2522/ptj.20080103 pmid: 19056854

19. Troosters T, Casaburi R, Gosselink R, Decramer M. Pulmonary rehabilitation in chronic obstructive pulmonary disease. America J Respirato Critical Care Med. 2005;172(1):19-38. doi: 10.1164/rccm.200408-1109SO pmid: 15778487

20.Jo M-R, Kim N-S, Ju-Hyeon Jung PT M. The effects of respiratory muscle training on respiratory function, respiratory muscle strength, and cough capacity in stroke patients. J Korean Societ Physic Med. 2014;9(4):399-405. doi: 10.13066/kspm.2014.9.4.399

21. Moodie L, Reeve J, Elkins M. Inspiratory muscle training increases inspiratory muscle strength in patients weaning from mechanical ventilation: a systematic review. J Physiotherap. 2011;57(4):213-221. doi: 10.1016/S1836-9553(11)70051-0 
22.Faul F, Erdfelder E, Lang AG, Buchner A. G* Power 3: A flexible statistical power analysis program for the social, behavioral, and biomedical sciences. Behav Res Method. 2007;39(2):175-191. doi: 10.3758/BF03193146 pmid: 17695343

23. Hicks GE, Fritz JM, Delitto A, Mishock J. Interrater reliability of clinical examination measures for identification of lumbar segmental instability. Arch Physic Med Rehabilit. 2003;84(12):1858-1864. doi: 10.1016/S0003-9993(03)00365-4

24. Saghaei M. Random allocation software for parallel group randomized trials. BMC Med Res Methodol. 2004;4(1):26. doi: 10.1186/1471-2288-4-26 pmid: 15535880

25. Boucher JA, Preuss R, Henry SM, Dumas JP, Larivière C. The effects of an 8-week stabilization exercise program on lumbar movement sense in patients with low back pain. BMC Musculoskeletal Disorder. 2016;17(1):23. doi: 10.1186/s12891-016-0875-4 pmid: 26762185

26. Hollander DB, Durand RJ, Trynicki JL, Larock D, Castracane VD, Hebert EP, et al. RPE, pain, and physiological adjustment to concentric and eccentric contractions. Med Sci Sport Exercise. 2003;35(6):1017-1025. doi: 10.1249/01.MSS.0000069749.13258.4E pmid: 12783051

27. Kim DY, Lee SH, Lee HY, Lee HJ, Chang SB, Chung SK, et al. Validation of the Korean version of the oswestry disability index. Spine. 2005;30(5):E123-127. doi: 10.1136/bjsm.2004.017350 pmid: 16431995

28. Cleland JA, Childs JD, Whitman JM. Psychometric properties of the Neck Disability Index and Numeric Pain Rating Scale in patients with mechanical neck pain. Arch Physic Med Rehabilit. 2008;89(1):69-74. doi: 10.1097/01.brs.0000157172.00635.3a

29. Joo MK, Kim TY, Kim JT, Kim SY. Reliability and validity of the Korean version of the fear-avoidance beliefs questionnaire. Physic Therap Korea. 2009;16(2):24-30. doi: 10.1016/j.apmr.2007.08.126 pmid: 18164333

30.Park DS, Lee DY, Choi SJ, Shin WS. Reliability and validity of the balancia using wii balance board for assessment of balance with stroke patients. $J$ Korea Academ Indust Cooperation Societ. 2013;14(6):2767-2772. doi: 10.1177/0269215512458684 pmid: 22960241

31.Lee JS, So YS, Kim MJ, Moon SJ, Jang SD, Kim YJ. Effects of the Lumbar stabilization exercise on scoliosis, Local muscle area, VAS and muscle function in female university students. Exerc Sci. 2011;20:61-71. doi: 10.5762/KAIS.2013.14.6.2767

32. Mikkelsson LO, Nupponen H, Kaprio J, Kautiainen H, Mikkelsson M, Kujala UM. Adolescent flexibility, endurance strength, and physical activity as predictors of adult tension neck, low back pain, and knee injury: a 25 year follow up study. British J Sports Med. 2006;40(2):107-113. doi: 10.15857/ksep.2011.20.1.61

33. Han KS, Lee KS, Kim GD. Effects of obesity on the weight distribution and lumbar extension strength in female patients with chronic low back pain. Korean J Sport Sci. 2010;19(3):937-945.

34. O'Sullivan PB, Burnett A, Floyd AN, Gadsdon K, Logiudice J, Miller D, et al. Lumbar repositioning deficit in a specific low back pain population. Spine. 2003;28(10):1074-1079. doi: 10.1097/00007632200305150-00022 pmid: 12768152

35.Comerford MJ, Mottram SL. Movement and stability dysfunction-contemporary developments. Manual Therap. 2001;6(1):15-26. doi: 10.1054/math.2000.0388 pmid: 11243905

36.Park JB, An SH. The effects of exercise on lumbar stabilization and a complex exercise in muscle, pains and index of disabilities in activities of chronic low back pain. Korean J Sport Sci. 2017;26(3):10191031. doi: 10.35159/kjss.2017.06.26.3.1019

37.Lew HL, Jerger JF, Guillory SB, Henry JA. Auditory dysfunction in traumatic brain injury. J Rehabilit Res Develop. 2007;44(7). doi: 10.1682/JRRD.2007.09.0140 pmid: 18075949

38. Hungerford B, Gilleard W, Lee DC. Altered patterns of pelvic bone motion determined in subjects with posterior pelvic pain using skin markers. Clinical Biomechanic. 2004;19(5):456-464. doi: 10.1016/j.clinbiomech.2004.02.004 pmid: 15182980

39. Sahrmann S. Diagnosis and Treatment of Movement Impairment Syndromes-E-Book: Elsevier Health Sciences; 2013.

40.Teixeira-Salmela LF, Parreira VF, Britto RR, Brant TC, Inácio ÉP, Alcântara TO, et al. Respiratory pressures and thoracoabdominal motion in community-dwelling chronic stroke survivors. Archiv Physic Med Rehabilit. 2005;86(10):1974-1978. doi: 10.1016/j.apmr.2005.03.035 pmid: 16213241 
41. Sutbeyaz ST, Koseoglu F, Inan L, Coskun O. Respiratory muscle training improves cardiopulmonary function and exercise tolerance in subjects with subacute stroke: a randomized controlled trial. Clinic Rehabilitat. 2010;24(3):240-250. doi: 10.1177/0269215509358932 pmid: 20156979

42. Kim JH, Park JH, Yim J. Effects of respiratory muscle and endurance training using an individualized training device on pulmonary function and exercise capacity in stroke patients. Med Sci Monitor Int Med J Experimental Clinical Res. 2014;20:2543. doi: 10.12659/MSM.891112 pmid: 25488849 